\title{
Optogenetic activation of amygdala projections to nucleus accumbens can arrest conditioned and unconditioned alcohol consummatory behavior
}

\author{
E. Zayra Millan ${ }^{*}, 1$, H. Amy Kim ${ }^{1}$, and Patricia H. Janak ${ }^{1,2}$ \\ ${ }^{1}$ Department of Psychological and Brain Sciences, Krieger School of Arts and Sciences, Johns \\ Hopkins University, Baltimore MD 21218 \\ ${ }^{2}$ Solomon H. Snyder Department of Neuroscience, Johns Hopkins School of Medicine, Johns \\ Hopkins University, Baltimore MD 21205
}

\begin{abstract}
Following a Pavlovian pairing procedure, alcohol-paired cues come to elicit behavioral responses that lead to alcohol consumption. Here we used an optogenetic approach to activate basolateral amygdala (BLA) axonal terminals targeting the shell of nucleus accumbens (AcbSh) and investigated a possible influence over cue-conditioned alcohol seeking and alcohol drinking, based on the demonstrated roles of these areas in behavioral responding to Pavlovian cues and in feeding behavior. Rats were trained to anticipate alcohol or sucrose following the onset of a discrete conditioned stimulus (CS). Channelrhodopsin-mediated activation of the BLA-to-AcbSh pathway concurrent with each CS disrupted cued alcohol seeking. Activation of the same pathway caused rapid cessation of alcohol drinking from a sipper tube. Neither effect accompanied an overall change in locomotion. Finally, the suppressive effect of photoactivation on cued-triggered seeking was also evidenced in animals trained with sucrose. Together these findings suggest that photoactivation of BLA terminals in the AcbSh can override the conditioned motivational properties of reward-predictive cues as well as unconditioned consummatory responses necessary for alcohol drinking. The findings provide evidence for a limbic-striatal influence over motivated behavior for orally-consumed rewards, including alcohol.
\end{abstract}

\section{Keywords}

ethanol; Pavlovian; conditioning; reward; learning; appetitive; consummatory

\footnotetext{
Correspondence to: Patricia H. Janak, Ph.D., Department of Psychological and Brain Sciences, Johns Hopkins University, Dunning Hall Room 246, 3400 N. Charles Street, Baltimore, MD 21218, patricia.janak@jhu.edu or E. Zayra Millan, Ph.D., School of Psychology, University of New South Wales, UNSW Sydney NSW 2052, Sydney Australia, Zayra.millan@unsw.edu.au. Present address: School of Psychology, University of New South Wales, Sydney, Australia 2052

Publisher's Disclaimer: This is a PDF file of an unedited manuscript that has been accepted for publication. As a service to our customers we are providing this early version of the manuscript. The manuscript will undergo copyediting, typesetting, and review of the resulting proof before it is published in its final citable form. Please note that during the production process errors may be discovered which could affect the content, and all legal disclaimers that apply to the journal pertain.

Financial Disclosure

Drs. E.Z. Millan and P.H. Janak report no biomedical financial interests or potential conflicts of interest.
} 


\section{Introduction}

The motivational properties of alcohol-associated cues contribute critically to the relapsing nature of alcohol use disorders (Brandon et al., 2007; Courtney et al., 2016; Heinz et al., 2009; Schacht et al., 2013). In humans, alcohol cues can increase self-report of craving, induce approach and attentional bias, impair behavioral control, and increase alcohol consumption (Field and Cox, 2008; Field and Duka, 2002; Jasinska et al., 2014; Jones et al., 2013; Kreusch et al., 2013; Wiers et al., 2014). Similarly, in animal models, alcohol-related cues can invigorate and reinstate instrumental seeking (Chaudhri et al., 2008a; Corbit and Janak, 2007, 2016; Dayas et al., 2008; Krank, 2003; Krank et al., 2008; Nie and Janak, 2003), elicit cue approach (Krank, 2003; Krank et al., 2008; Srey et al., 2015), and also trigger reward approach and consumption (Chaudhri et al., 2008b, 2010; Hauser et al., 2016; Knight et al., 2016; Krank, 2003; Krank et al., 2008; Millan et al., 2015; Remedios et al., 2014; Srey et al., 2015). In many cases, these multiple behavioral effects of alcohol-paired cues may be observed within the same behavioral session and within the same subjects (Krank et al., 2008; Srey et al., 2015). Recently we sought to isolate the impact of alcohol cues on alcohol approach and consumption using a Pavlovian design in which auditory cue presentations are followed by alcohol delivery; using this procedure, alcohol-paired cues increase entries into a recessed reward port where alcohol is delivered for oral consumption (Chaudhri et al., 2008b, 2010; Millan et al., 2015; Remedios et al., 2014; Sparks et al., 2014), allowing study of the neural mechanisms underlying cue-elicited alcohol approach and consumption.

We previously found that pharmacological inactivation of the basolateral amygdala (BLA) or the nucleus accumbens reduces these Pavlovian cue-elicited port entries for alcohol (Chaudhri et al., 2010, 2013; Millan et al., 2015). Multiple lines of evidence suggest that reward-paired cues impact reward seeking in part though activation of excitatory projections from the BLA to the nucleus accumbens (Ambroggi et al., 2008; Beyeler et al., 2016; Everitt et al., 1989, 1999; Gremel and Cunningham, 2008; Namburi et al., 2015). In this conception, excitation of BLA neurons by reward-paired cues would excite relevant populations of accumbens neurons that in turn activate appetitive behavior, i.e., reward-seeking actions. In agreement with this, the onset of cue-evoked excitation in the BLA, measured as increases in spike rates of single units, generally precedes the onset of cue excitations in the accumbens, and pharmacological inactivation of the BLA reduces excitatory cue responses in the accumbens (Ambroggi et al., 2008). These findings might suggest that direct activation of BLA-to-accumbens projections would facilitate cue-elicited port entries for alcohol.

On the other hand, a substantial body of work implicates decreases, rather than increases, in nucleus accumbens neuronal firing, especially within the shell subregion (AcbSh), in the actual reward consummatory behavior itself (Kelley and Swanson, 1997; Krause et al., 2010; Maldonado-Irizarry et al., 1995; Nicola et al., 2004; O'Connor et al., 2015; Roitman et al., 2005; Stratford and Kelley, 1997; Taha and Fields, 2005, 2006). For example, in single-unit in vivo recording studies of accumbens neurons, considerably more inhibitions, measured as decreases in spike activity, than excitations are typically observed during oral consumption of sucrose (Day et al., 2006; Janak et al., 2004; Nicola et al., 2004; Wan and Peoples, 2008). These decreases in neural firing are observed time-locked to consummatory responses 
during opportunities for free-feeding and in the setting of conditioned behavior. For example, O'Conner and colleagues (2015) recently showed that spiking activity in dopamine D1-receptor (D1R)-expressing AcbSh medium spiny neurons (MSN) decreased upon initiation and during maintenance of liquid fat consumption from a sipper tube. In addition, when recording in a Pavlovian port-approach procedure, in which a light cue was paired with sucrose delivery into a recessed port, Wan and Peoples (2006) found that $>50 \%$ of recorded accumbens neurons showed a long-lasting inhibition that paralleled the time in the reward port, with half of these inhibitions beginning after cue onset and before port entry. Since the subjects approached and entered the port during the cue prior to reward delivery, the inhibitions were proposed to potentially regulate the approach and port entry behavior as well as the subsequent consumption (Wan and Peoples, 2006). Similar long-lasting inhibitions in the nucleus accumbens during cue approach have been reported by Day and colleagues (2006) recording in a Pavlovian autoshaping procedure. Importantly, observation of the onset of accumbal inhibitions and reward port entry and exit, as well as sipper tube contact, suggest that for the most part the inhibitions are permissive for consummatory behavior rather than directly correlated with motoric actions of licking (Nicola et al., 2004; Taha and Fields, 2005).

In agreement with the notion that accumbal inhibitions permit, or gate, consummatory behavior, classic studies demonstrated that pharmacological inhibition of the AcbSh with GABAergic agonists or AMPA glutamate receptor antagonists induces eating even in sated subjects (Kelley, 2004; Kelley and Swanson, 1997; Maldonado-Irizarry et al., 1995; Stratford and Kelley, 1997), and recent studies show that optogenetic inhibition of D1R MSNs does as well (O'Connor et al., 2015). Conversely, when targeted directly through electrical, optogenetic, or pharmacological means, activation of the AcbSh can diminish reward consumption (Krause et al., 2010; O'Connor et al., 2015; Stratford et al., 1998). A recent study reported that photoactivation of glutamatergic terminals in the AcbSh in mice decreased licking behavior for sucrose (Prado et al., 2016).

Because alcohol is consumed orally, one might expect similar inhibitory neural signals to accompany alcohol intake. Indeed, spike activity decreases during port entries when alcohol is consumed have been recorded in the AcbSh (Janak et al., 1999). Together, these findings support a suppressive influence for AcbSh neural activity over approach and consumption of rewards. The AcbSh receives excitatory glutamatergic inputs from multiple corticolimbic and thalamic sites, including the BLA (Brog et al., 1993; Kelley et al., 1982; McDonald, 1991; Thompson and Swanson, 2010), which are candidates for regulating AcbSh activity relevant to consumption. Taken with the experimental evidence provided above, the hypothesis that activation of excitatory BLA-to-AcbSh projections could decrease, not increase, both cue-elicited approach and consumption of oral alcohol emerges. Here we tested this idea.

We show that channelrhodopsin(ChR2)-mediated optogenetic activation of BLA-AcbSh innervation during the onset of an alcohol-predictive cue significantly disrupts Pavlovian cue-triggered alcohol approach under non-reinforced and reinforced test conditions. Second, this disruption is not specific for conditioned, cue-elicited behavior, as activation of this pathway can interrupt alcohol drinking itself. Finally, we show that the suppressive effect of 
BLA-AcbSh stimulation on conditioned behavior is generalizable to non-drug consummatory rewards. Taken together, these findings support the notion that distinct patterns of neural activity in the accumbens regulate appetitive and consummatory behaviors, with excitation biasing away from consummatory behavior, and provide new information on the neural regulation of cue-elicited alcohol intake.

\section{Experimental Procedures}

\section{Subjects}

Experimentally-naïve male Long-Evans rats (Harlan, IN; 200-215g) were individually housed in ventilated polycarbonate cages in a temperature $\left(21^{\circ} \mathrm{C}\right)$ and light-regulated vivarium (lights on $7 \mathrm{am}, 12 \mathrm{~h}$ light/dark cycle) with partial enrichment. Food and water were freely available throughout the duration of these studies. All procedures were approved by the institutional Animal Care and Use Committee.

\section{Surgery}

Rats were anesthetized with isoflurane and infused bilaterally in BLA with adeno-associated viruses (AAV; $10^{12}$ infectious units $\mathrm{ml}^{-1}$; UNC Viral Vector Core, Chapel Hill, NC) expressing channelrhodopsin (ChR2; rAAV5/CaMKII-hChR2(H134R)-eYFP-WPRE) or control eYFP (rAAV5/CaMKII-eYFP-WPRE). BLA coordinates from bregma were: AP, -2.85 ; $\mathrm{ML}, \pm 4.85$; DV, -8.85 . Injections were delivered in a volume of $.5 \mu \mathrm{l}$, at a rate of $.1 \mu \mathrm{l}$ $\mathrm{min}^{-1}$, via custom-made $31 \mathrm{~g}$ injector needles. Injections were left in place for an additional 10 min to allow diffusion of viral particles away from the injection site. Fiber optic cannulae (300 $\mu \mathrm{m}$ core diameter) attached to $12.7 \mathrm{~mm}$ stainless steel ferrules were bilaterally implanted in AcbSh with stereotaxic coordinates AP: +1.35 , ML: \pm 1.7 ( $6^{\circ}$ angle), DV: -6.6 from bregma. Rats were postoperatively treated with buprenorphine $(1.2 \mathrm{mg} / \mathrm{kg}$, s.c.) and carprofen $(5 \mathrm{mg} / \mathrm{kg}$, s.c.) analgesics.

\section{Homecage Alcohol Pre-Exposure}

For alcohol studies, rats were acclimatized to the taste and pharmacological effects of alcohol (ethanol; 15\% v/v) using a chronic intermittent schedule as described in previous studies (Millan et al., 2015; Remedios et al., 2014; Simms et al., 2008). Alcohol intake $(\mathrm{g} / \mathrm{kg})$ on the last day of homecage access prior to and following surgery is shown in Table 1. Intake on these days was not significantly different, with no significant differences between groups. Rats used in the sucrose study had no prior history with alcohol.

\section{Alcohol Pavlovian Training}

Training occurred in standard conditioning chambers (Med Associates, St Albans, VT) encased in sound-attenuating chambers. A single recessed port receptacle was exposed in the center panel of a sidewall. Prior to conditioning, rats received a $1 \mathrm{hr}$ port-training session involving fifteen deliveries of $0.2 \mathrm{ml}$ alcohol (ethanol; $15 \% \mathrm{v} / \mathrm{v}$ ) into the port at a variable interval (VI) of 240s. Subsequent Pavlovian cue conditioning sessions consisted of fifteen pairings of a 10s auditory conditioning stimulus (CS, white noise, $10-25 \mathrm{kHz}, 20 \mathrm{~dB}$ above baseline) with $0.2 \mathrm{ml} 15 \%$ alcohol, which was delivered over $6 \mathrm{~s}$ starting at $4 \mathrm{~s}$ from cue onset 
and terminating with cue offset. There was a variable interval of 240s between CS presentations. A photocell beam detected port entries.

Rats received 10d of Pavlovian cue conditioning. Total alcohol delivered per session was $3 \mathrm{~mL}$. Over the last $3 \mathrm{~d}$ of training, rats were tethered to custom optical patch cables $(200 \mu \mathrm{m}$ core diameter) encased in protective stainless-steel furcation tubing to habituate animals to the testing conditions.

\section{Sucrose Pavlovian Training}

Rats received similar Pavlovian cue conditioning as described with $0.2 \mathrm{ml}$ sucrose $(10 \% \mathrm{v} / \mathrm{v})$ delivered instead of alcohol.

\section{Photoactivation of BLA Terminals in the AcbSh During Cued Alcohol Seeking}

At the completion of conditioning, rats expressing ChR2 or control eYFP underwent testing to determine the impact of BLA terminal stimulation on cue-elicited alcohol seeking. Two animals failed to acquire conditioned behavior during training and were excluded from further testing. Photoactivation was induced by bilateral intracranial delivery for $5 \mathrm{~s}$ of $473 \mathrm{~nm}$ light ( $20 \mathrm{~Hz}$ pulses, $5 \mathrm{~ms}$ pulse duration, $\sim 25 \mathrm{~mW}$ illumination at fiber tip), concurrent with CS onset. Therefore, the duration of photostimulation was limited to the first half of each 10s CS. Since we predicted that photoactivation of BLA-to-AcbSh neurons would impact cue-conditioned behavior, the abbreviated window of photostimulation allowed us to target the initiation of cue-elicited behavior.

Non-reinforced extinction test (no alcohol delivered)-The extinction test was conducted over two sessions. In one session, photostimulation was delivered with every CS trial ("on" condition). In the other, photostimulation was withheld ("off" condition). Test conditions were counterbalanced in order and separated by two re-training sessions. There were $15 \mathrm{CS}$ trials as in training. The absence of alcohol reward on test allowed assessment of the behavioral impact of the alcohol cue in isolation from the reinforcing, sensory, or pharmacological properties of the alcohol solution. In this and all subsequent tests, laser light was bilaterally delivered through optical patch cables that connected a light-splitting rotary joint interfaced with a fiber-coupled diode-pumped solid-state (DPSS) laser.

Reinforced tests (alcohol is delivered)—Rats were subsequently tested in two reinforced sessions of cued alcohol seeking. For Reinforced Test I, on the first test day after extinction (described above), rats were re-exposed to CS-alcohol pairings and received photostimulation on all CS trials, with alcohol delivered as usual 4 seconds after cue onset, resulting in a 1s overlap between optical stimulation and alcohol delivery. On the following test day, rats underwent Reinforced Test II, in which the onset of alcohol delivery was shifted forward so that it commenced simultaneously with the onset of both the CS and laser. This allowed us to ask whether behavioral disruptions induced by photostimulation of BLA terminals were specific to anticipatory behavior or if behavior would be disrupted when sensory properties (e.g. sight and smell) of the alcohol were present at the time of photostimulation. On this second reinforced test, photostimulation was withheld on the first three trials to provide an initial baseline of behavior, and was then delivered, randomized, on 
half the CS trials (trials 4,5,8,10,12,13,14, and 16), with the same sequence across subjects, allowing for a same-day within-test comparison.

All test behavior was video recorded. To further characterize the effects of photostimulation, conditioned behavior during the first 5 s of the CS was manually scored from video recordings of Reinforced Test II. Scored behaviors included: ambulation and ambulation direction (towards or away from port). Also, responses were termed abortive if the animal crossed the boundaries of a defined port area followed by ambulation in the opposite direction. The port area was defined as a quadrilateral region bounded by the width of the port and with a depth defined by the second grid floor rod closest to the port.

\section{Photoactivation of BLA Terminals in the AcbSh During Homecage Alcohol Access}

At the conclusion of Pavlovian testing, a subset of animals was transported to the behavioral testing room and received overnight homecage intermittent access over $2 \mathrm{~d}$ to encourage homecage drinking in the testing room. Duration of access to alcohol was reduced gradually over 4-7d until animals were accustomed to drinking within a $10 \mathrm{~min}$ observation period, with all subjects typically initiating intake upon insertion of the alcohol bottle. Rats were bilaterally tethered to optical patch cables on the last two days of access to acclimatize them to the testing conditions. Alcohol bottles were weighed prior to and following alcohol access.

On test, photostimulation $(20 \mathrm{~Hz}, 5 \mathrm{~ms}$ pulse, $\sim 25 \mathrm{~mW}$ at fiber tip) was manually triggered following the onset of the initial drinking bout. Lick frequency (tongue protrusions at the sipper) was manually scored from video recordings examined frame-by-frame during the first 10 s of photostimulation and during a pre-stimulation baseline period. ChR2 rats received either $10 \mathrm{~s}(\mathrm{n}=4)$ or $120 \mathrm{~s}(\mathrm{n}=6)$ of photostimulation; these data were analyzed together. eYFP rats received 120s of stimulation. Non-drinking snout contact with the sipper tube was scored for the entire duration of photostimulation from video recordings.

\section{Photoactivation of BLA Terminals in the AcbSh During Pavlovian Cued Sucrose Seeking}

Rats received Sucrose Pavlovian Training and then were tested as above during extinction. ChR2 and eYFP groups were trained and analyzed separately.

\section{Immunohistochemistry}

At the conclusion of the study rats were deeply anesthetized with sodium pentobarbital $(100 \mathrm{mg} / \mathrm{kg}$, i.p.) and perfused transcardially with $50 \mathrm{ml}$ of $0.9 \%$ saline followed by $400 \mathrm{ml}$ of $4 \%$ paraformaldehyde in $0.1 \mathrm{M}$ phosphate buffer $(\mathrm{PB}), \mathrm{pH} 7.4$. Brains were postfixed for $1 \mathrm{~h}$ in the same fixative and placed in $20 \%$ sucrose overnight. Tissue was sectioned coronally at $50 \mu \mathrm{m}$, stored in a phosphate buffered solution (PBS), and processed using immunofluorescent histochemistry for detection of eYFP. Free floating sections were washed in a solution of PBS with $0.2 \%$ Triton $\mathrm{X}-100$ and $0.2 \%$ bovine serum albumin (PBST) for 20min at room temperature and then incubated in a blocking solution made of PBST with 10\% normal donkey serum (Jackson ImmunoResearch, number 017-000-121) for 30min. Sections were incubated overnight at $4{ }^{\circ} \mathrm{C}$ with gentle agitation in a mouse antiserum against GFP (mouse anti-GFP, 1:1500, Invitrogen, A11120) in PBST. After 
subsequent $3 \times 10$ min washes in PBST, sections were incubated in a secondary antibody (AlexaFluor 488 donkey anti-mouse, 1:200, Invitrogen) in PBST for $2 \mathrm{~h}$ at room temperature. Finally sections were washed in PBS and coverslipped with Vectashield mounting medium containing DAPI (VWR, \#H-1500). Fluorescent images in BLA and AcbSh were digitally captured using a Hamamatsu ORCA-Flash4.0 attached to a Zeiss AxioImager M2 microscope at $5 \times$ magnification and ZEN software (Carl Zeiss Microscopy). Histological examination revealed that bilaterally-positioned viral injections in BLA and fiber optic cannulae in AcbSh was successfully achieved in 30 experimental subjects distributed across the experiments as follows (alcohol experiments: $C h R 2, \mathrm{~N}=10$ and eYFP, N=7; Sucrose experiment: $C h R 2, \mathrm{~N}=8$ and $e Y F P, \mathrm{~N}=5$ ). There were no lesions detected in the tissue; eYFP-expressing terminals surrounded the ventral tip of the implant. Animals with misplaced injections or implants were excluded.

\section{Statistical Methods}

Data were analyzed using planned orthogonal contrasts with between-subjects (ChR2 vs Control) and within-subjects (illumination on vs off) factors in a mixed-model multivariate ANOVA. Significance was assessed against a type I error rate of 0.05 .

\section{Results}

To test the effects of activation of BLA excitatory projections to the AcbSh, rats were infused with ChR2-expressing virus in the BLA, and optical fibers were placed in the AcbSh $(\mathrm{N}=10$; Figure $1 \mathrm{~A}-\mathrm{C})$; control subjects were infused with an eYFP-only virus $(\mathrm{N}=7)$. Histological examination revealed densely labeled eYFP expression localized to the basal portion of BLA; projection fibers spanned medial (shell) and lateral (core) sections of the nucleus accumbens, and eYFP-expressing terminals typically surrounded the ventral tip of the implant. An example infection in BLA and AcbSh for ChR2 can be seen in Figures 1B and $1 \mathrm{C}$, respectively.

\section{Photoactivation of BLA Terminals in the AcbSh Suppresses Both Reinforced and Non- reinforced Pavlovian Cued Alcohol Seeking}

To test the behavioral impact of stimulating BLA inputs in AcbSh during conditioned responding to an alcohol cue, rats were first trained to associate an auditory CS with alcohol delivery. Across training, there were on average significantly more port entry conditioned responses (CRs) during the CS than preCS baseline $\left(\mathrm{F}_{(1,15)}=60.12, p<.001\right)$ congruent with acquisition of cued alcohol seeking. Prior to test, there were no significant differences in conditioned port entries between ChR2 and eYFP groups on the final day of training or across training days ( $p$ values $>.38$; mean \pm SEM normalized port entries for final day of training: ChR2, $20.2 \pm 4.53$; eYFP, 26.43 \pm 5.13 ).

Non-reinforced CS (Extinction test)—Rats were first tested for the effect of ChR2 activation on cued alcohol seeking in the absence of the alcohol reward. This removed the sensory and pharmacological influence of alcohol on test. They were tested across two days, with and without stimulation (i.e., "on" versus "off" condition), counterbalanced in order, separated by 2 days of retraining. Across trials, responding reduced as expected for an 
extinction procedure, but this was differentially impacted by photoactivation which overall reduced the frequency of cue-elicited port entries (light main effect, on $\mathrm{v}$ off: $\mathrm{F}_{(1,15)}=4.71$, $p<.05$ ), and this was selective for ChR2 (group $\times$ light, $\mathrm{F}_{(1,15)}=9.84, p<.01$, Figure 1D). This effect was mediated by ChR2-induced behavioral changes during the $5 \mathrm{~s}$ laser-on period. When looking only during this $5 \mathrm{~s}$ window, both the probability of a port entry (group main effect: $\mathrm{F}_{(1,15)}=16.89, p<.05$; group $\times$ light: $\mathrm{F}_{(1,15)}=7.66, p<.01$; Figure $\left.1 \mathrm{E}\right)$ and the number of port entries (group main effect: $\mathrm{F}_{(1,15)}=8.15, p<.05$; group $\times$ light, $\mathrm{F}_{(1,15)}=7.02, p<.01$, Figure $1 \mathrm{~F}$ ) were significantly reduced in the $\mathrm{ChR} 2$ group. Follow-up simple effects comparisons, "On" v "Off" for these measures were also significant in group ChR2 but not eYFP, and are described in Figure 1.

Reinforced tests-We next examined the effect of ChR2 activation under reinforced CS conditions, using the same reward delivery timing as during training. The question was whether on any given trial, port entry responding could be recovered at the termination of photoactivation if alcohol was again made available to maintain performance. Thus on this test, photoactivation co-occurred with the first $5 \mathrm{~s}$ of a $10 \mathrm{~s} \mathrm{CS}$; termination of photoactivation occurred $1 \mathrm{~s}$ after onset of alcohol delivery (commencing $4 \mathrm{~s}$ from CS onset). When performance was examined within the $5 \mathrm{~s}$ photoactivation window, ChR2 activation significantly reduced the probability (group main effect: $\mathrm{F}_{(1,15)}=5.21, p<.05$, Figure $2 \mathrm{~A}$ ) and frequency of port entries (group main effect: $\mathrm{F}_{(1,15)}=7.61, p<.05$, Figure 2B). ChR2 activation also delayed the latency to initiate a port entry after cue onset (group main effect: $\mathrm{F}_{(1,15)}=18.49, p<.05$, Figure 2C); as seen in Figure 2C, the latency to enter the port was typically delayed until after laser offset in $\mathrm{ChR} 2$ subjects. These findings suggest that photoactivation prior to alcohol delivery disrupted conditioned port entries. Unlike the extinction test, the effects of photoactivation during this reinforced test were temporally specific since animals retained the capacity to perform cued alcohol seeking, albeit, at a delayed latency, presumably due to the presence of alcohol. Thus, when the entire 10s cue period was taken into account, photoactivation did not significantly affect the probability of responding during the CS ( $p$ values $>0.33$ ), indicating that stimulation does not impair motivation for or the ability to consume alcohol upon stimulation offset.

Thus far, photostimulation onset has been dissociated from alcohol delivery onset. We next asked, using the same subjects, whether the photoactivation effect was specific to conditioned cue responding such that the presence of alcohol would override the ChR2induced behavioral inhibition. Thus, in this test - Reinforced Test II - the onset of all three events, alcohol delivery, alcohol cue presentation and photostimulation, occurred concomitantly. This test differed from previous tests in that half of the CS trials were paired with photostimulation, allowing for a within-test comparison. One rat in the ChR2 group was unable to be tested in this condition due to headcap malfunction.

Photoactivation was withheld on the first three CS trials, which served as a baseline. Unexpectedly, $\mathrm{ChR} 2$ rats made significantly fewer numbers of port entries across the first three baseline trials relative to eYFP (group main effect: $\mathrm{F}_{(1,14)}=10.88, p<.05$ ). This may reflect carryover from prior ChR2-induced suppression of responding from Reinforced Test I. Thus for the following analyses, groups ChR2 and eYFP were examined separately. Nevertheless, for ChR2 rats, whether inclusive or exclusive (shown) of initial baseline trials, 
the probability of emitting a port entry during the $5 \mathrm{~s}$ photoactivation window was significantly reduced (light main effect, on $v$ off: $\mathrm{F}_{(1,8)}$ values $>14.26, p$ values $<.05$; Figure 2D). ChR2 stimulation also reduced the number of port entries during the photostimulation window (light main effect, on $v$ off: $\mathrm{F}_{(1,8)}=11.83, p<.05$; Figure $2 \mathrm{~F}$ ) and delayed the latency to emit the first port entry after cue onset (mean \pm SEM: On, 4.93 \pm .62 ; Off, 3.34 \pm .43 ; $\left.\mathrm{F}_{(1,8)}=7.06, p<.05\right)$. Similar comparisons for control group eYFP were not significant ( $p$ values>.14, Figures 2E,G). Therefore, ChR2 activation of BLA terminals in AcbSh was sufficient to prevent cued alcohol seeking despite the presence of alcohol at the moment of photoactivation. Moreover, similar to the prior reinforced test, the effects were within the timeframe of photoactivation since overall cued performance was not significantly affected when including the $5 \mathrm{~s}$ with no stimulation (overall frequency of port entries during the CS, $p=.35$; probability of emitting a port entry, $p=.06$ ).

Are the decreases in conditioned port entries due to an arrest of movement? To further characterize the behavioral effects of photoactivation we examined video-recorded behavior of ChR2-expressing rats performing this reinforced test during the first $5 \mathrm{~s}$ of the CS across all trials (ie, photoactivation period; see Methods). The probability of any ambulatory activity was not significantly different between trials with versus without photoactivation ( $p=.75$, Figure $2 \mathrm{H}$, 'Total'). When the direction of ambulation was examined, there was also no effect of photoactivation on ambulation directed towards the port ( $p=1$, Figure $2 \mathrm{H}$ ). However, there was a significant effect of photoactivation in ambulation away from the port $\left(\mathrm{F}_{(1,8)}=14.29, p<.05\right.$, Figure $\left.2 \mathrm{H}\right)$. These data confirm that photoactivation did not impair ambulatory activity, although the distribution of that activity may be altered to favor movement away from the port.

\section{Photoactivation of BLA Terminals in the AcbSh Interrupts Alcohol Drinking}

The reinforced test above demonstrated that ChR2 activation of BLA terminals in the AcbSh is sufficient to disrupt conditioned behavior despite the availability of alcohol at the time of photoactivation. However, it could not be determined from this test whether photoactivation of this pathway would disrupt alcohol consumption once it had been initiated, or if this was an effect on initiation. We therefore tested this directly in a homecage alcohol consumption test in a subset of subjects (see Methods).

In the control group, eYFP ( $\mathrm{N}=5)$, laser onset times, garnered from video analysis, were 5$25 \mathrm{~s}$ following the first lick. There was no significant difference in lick rate during a $5 \mathrm{~s}$ prestimulation baseline compared with lick rate during the first 10s of laser $(p=.66)$. Figure $3 \mathrm{~A}$ shows lick rate across the first 20s of photostimulation to illustrate the persistence of licking in eYFP controls. For ChR2 (N=10) rats, laser onset ranged 13-16s from the first lick. Lick rate during the first 10s of $\mathrm{ChR} 2$ activation was significantly lower than during a 10 s prestimulation period (Figure $3 \mathrm{~B}, \mathrm{~F}_{(1,9)}=59.09, p<.05$ ). Individual cessation latencies shown in Figure $3 \mathrm{C}$ indicate that all subjects abruptly ceased licking within 1-4 s. Comparing between groups, lick rates during the photoactivation period were significantly different between eYFP and ChR2 groups (group main effect: $F_{(1,13)}=9.23 ; p<.05$ ), but not during a 5 s prestimulation period $(p=.73$ ). Similarly, the ratio of lick suppression (number of 
licks during observation period minus baseline/total) was significantly different between groups (group main effect: $F_{(1,13)}=11.22 ; p<.05$, Figure 3D).

To further examine behavior at the time of photoactivation, we quantified non-drinking contact with the sipper tube during photoactivation to gauge the extent of behavioral disruption. We found that snout contact with the sipper tube during the entire photoactivation period was significantly elevated in group ChR2 relative to control eYFP animals (group main effect: $\left.\mathrm{F}_{(1,13)}=5.34, p<.05\right)$. Mean $( \pm \mathrm{SEM})$ frequencies of contact were: ChR2, $5.6 \pm 1.55$ and eYFP, $0.4 \pm .89$. This elevation is against a low baseline of behavior in eYFP animals, which were primarily engaged in drinking during the laser-on period. These findings suggest that motivational appetitive processes necessary to mediate behaviors, such as approach, remain intact during ChR2 activation in this preparation.

\section{Photoactivation of BLA Terminals in the AcbSh Suppresses Pavlovian Cued Sucrose Seeking}

Next, we examined whether the suppressive effects of photoactivation on cued alcohol seeking could generalize to conditioned responses reinforced with non-drug natural and palatable rewards such as sucrose. To test the behavioral impact of stimulating BLA inputs in AcbSh during conditioned responding to an auditory sucrose CS+, rats were infused with $\mathrm{ChR} 2$-expressing virus $(\mathrm{N}=8)$ or the control YFP virus $(\mathrm{N}=5)$ in the $\mathrm{BLA}$, and optical fibers were placed in the AcbSh (Figure 4 A-C). In contrast to the alcohol studies, ChR2 and eYFP animals were trained in separate cohorts and thus are analyzed separately. Across training, there were on average significantly more port entries during the CS than preCS baseline (ChR2: $\mathrm{F}_{(1,7)}=31.01, p<.05$; eYFP: $\left.\mathrm{F}_{(1,4)}=50.93, p<.05\right)$ indicating acquisition of cued reward seeking. Mean $( \pm$ SEM) numbers of normalized port entries on the last day of training were: ChR2: 30.5 ( \pm 5.478$)$; eYFP: $21.6( \pm 3.03)$.

Extinction test (non-reinforced CS)—As observed for Pavlovian responding for alcohol, photoactivation significantly reduced port entry probability (light main effect, on $\mathrm{v}$ off: $\mathrm{F}_{(1,7)}=11.66, p<.05$, Figure 4D), and frequency (light main effect, on $v$ off: $\mathrm{F}_{(1,7)}=6.22$, $p<.05$, Figure $4 \mathrm{E}$ ) of port entries, during the first $5 \mathrm{~s}$ of the CS, corresponding with the period of photoactivation. Similar comparisons for eYFP animals were not significant ( $p$ values>. 08; Figures 4D-E). Therefore, similar to alcohol-drinking rats, BLA-AcbSh pathway stimulation impaired non-reinforced cued reward seeking.

\section{Discussion}

We used an optogenetic approach to stimulate axonal terminals of BLA neurons targeting the ventromedial striatum, AcbSh, in animals conditioned to a cue signaling alcohol. We found that photoactivation of a BLA-to-AcbSh pathway acutely suppressed cue-triggered alcohol seeking, regardless of whether cues were reinforced or non-reinforced on test. Second, stimulating this pathway similarly disrupts unconditioned alcohol drinking as well as conditioned responding to cues signaling a non-alcoholic reward, sucrose. These findings suggest that photoactivation of BLA terminals in the AcbSh can interfere with the behavioral impact of Pavlovian conditioned reward cues and also the execution of unconditioned consummatory action, in agreement with the proposed permissive role of AcbSh neuronal 
inhibition in consummatory behavior (Kelley, 2004; Krause et al., 2010; Nicola et al., 2004; Taha and Fields, 2006) and in agreement with recent studies using optogenetics in the AcbSh to control feeding (O'Connor et al., 2015; Prado et al., 2016). The current findings confirm that alcohol consummatory behavior is under control of feeding circuits in the accumbens, as shown previously using opioid agonists (Richard and Fields, 2016; Zhang and Kelley, 2011) and GABA receptor subunit knockdown (Nie et al., 2011), and extend these findings to show that this control can be recruited by activation of BLA terminals.

\section{Photoactivation of BLA-to-AcbSh pathway suppresses cue-triggered reward seeking and alcohol drinking}

Based on prior studies implicating AcbSh in suppressing drug and alcohol seeking (Millan et al., 2010; Sutton et al., 2003) and reports correlating AcbSh neural activity with the suppression of consummatory behaviors (Holland et al., 2014; Krause et al., 2010; Roitman et al., 2010), we considered here the possibility that excitation of BLA terminals in AcbSh would suppress performance of conditioned alcohol-reinforced behavior. Our findings are consistent with this. Photoactivation of BLA-to-AcbSh neurons impaired cue-elicited alcohol-seeking. The effects were pronounced in the absence of alcohol (extinction). When alcohol was available on test, photoactivation disrupted behavior during the photoactivation period itself, which was only the first 5 seconds of the total 10 seconds of CS duration. Importantly, the reinforced tests show that this effect was temporally-specific since cueelicited behavioral responding was apparent after stimulation offset. These effects do not appear to result from non-specific disruption of motor ability since overall ambulatory capacity was unaltered by stimulation. Interestingly, photoactivation appeared to bias ambulatory behavior in the opposite direction to the port. Importantly, the observed effects on cued alcohol seeking were generalizable to sucrose-conditioned cues. It is not clear how our findings relate to a prior report of pharmacological inactivation of the AcbSh; this study found that muscimol into the AcbSh increased sucrose intake but decreased alcohol intake (Stratford and Wirtshafter, 2011); of note other studies find opioids increase both sucrose and alcohol intake (Richard and Fields, 2016; Zhang and Kelley, 2002). In general, the present findings are consistent with a long-recognized account of AcbSh as a locus of control over feeding (Kelley, 2004; O'Connor et al., 2015; Stratford and Kelley, 1997) and orofacial function (Koshikawa et al., 2011; Prinssen et al., 1994; Roitman et al., 2005), and are consistent with previous reports of interrupted sucrose licking following electrical stimulation of the AcbSh (Krause et al., 2010), and, conversely, elevated licking following photoinhibition of AcbSh (O'Connor et al., 2015).

Our findings suggest that appetitive behavior is sensitive to disruption from photoactivation of BLA terminals in the AcbSh. However, it is notable that some appetitive responses remained intact. For example, photoactivation suppressed conditioned responding to the alcohol cue in the maintenance test, and although ambulation in the direction of the port was reduced, this decrease was not significant, and rats still moved towards the port for $40 \%$ of trials. Second, although photoactivation interrupted alcohol drinking, animals continued to interact with the sipper tube during the alcohol drinking test. These within-test dissociations are intriguing and raise important questions about control over the sequence of rewardseeking actions, specifically between approach and "terminal", consummatory, responses, 
which are proposed to engage different learning systems (Chang and Smith, 2016; Naeem and White, 2016; Selleck and Baldo, 2017). The findings suggest the interesting possibility that consummatory responses/terminal responses, may be more sensitive to the influence of BLA-AcbSh innervation than more distal actions within the behavioral chain, a possibility awaiting future testing.

This idea is of interest in light of prior work on the role of accumbens BLA input in appetitive behavior. In particular, despite direct evidence for BLA modulation of excitatory cue-evoked neural signals in the Acb (e.g., Ambroggi et al., 2008) we could not improve behavioral reactions to conditioned cues by direct stimulation of BLA inputs into the AcbSh, indicating either that the broad disruption of a potentially sparse cue representation contributed to our observed impaired behavior, or that this type of excitatory cue response is not critical for promoting Pavlovian responses aimed directly at reward consumption, as opposed to the cue-elicited instrumental behaviors investigated in prior reports (Ambroggi et al., 2008), at least in the AcbSh, an interpretation we favor. Under this view, some excitatory signals from the BLA may be critical for eliciting/shaping appetitive, rather than consummatory, response (Ambroggi et al., 2008; Beyeler et al., 2016; Britt et al., 2012; Namburi et al., 2015; Stuber et al., 2011). It is possible appetitive responses may be driven more by BLA projections to the core rather than shell region of the accumbens, although this remains to be determined. Finally, future photoinhibition studies will be useful for parsing the specific role of the BLA-AcbSh pathway on shaping consummatory responses, particularly since antidromic activation can occur following pathway optical stimulation (Jennings et al., 2013) and could potentially affect collateral targets, including to the medial prefrontal cortex, ventral hippocampus, and central amygdala, of BLA-to-nucleus accumbens projector cells (Beyeler et al., 2016; Shinonaga et al., 1994).

It is not clear whether we would have seen similar effects of stimulating other excitatory glutamatergic inputs into the AcbSh although recent studies support a role for multiple inputs, including the prefrontal cortex and the thalamus, in reward seeking and consumption (Britt et al., 2012; Do-Monte et al., 2017; Prado et al., 2016; Selleck and Baldo, 2017; Stuber et al., 2011). For example, Britt et al found that mice will respond for activation of prefrontal, BLA, or hippocampual accumbal inputs (Britt et al., 2012). The prefrontal cortex has been suggested to be critical for behavior selection and for switching between appetitive and consummatory behavior (c.f.,(Selleck and Baldo, 2017). Additionally, activation of inputs from the paraventricular nucleus of the thalamus during instrumental nosepoking for sucrose decreases nosepoke responding, yet did not reduce ad libitum sucrose consumption (Do-Monte et al., 2017). Notably, our study used a stimulation train of five seconds, while others (c.f., Britt et al., 2012; Do-Monte et al., 2017) utilize stimulation trains ranging from one to fifteen seconds, which may drive AcbSh units more powerfully than typically observed; while there is utility in probing potential functionality using current optogenetics approaches, studies that attempt to mimic natural activity patterns using brief and low intensity stimulation are a future goal. To this end, optogenetic methods that mimic physiological tonic increases in nucleus accumbens dopamine have been shown to reduce consummatory responses for ethanol (Bass et al., 2013) and sucrose (Mikhailova et al., 2016), similar to the present findings. Further research is clearly required to delineate the 
circumstances during which input-specific activity might naturally occur to alter both natural and alcohol reward seeking and consuming.

\section{AcbSh heterogeneity in reward and aversion}

There has been increasing attention on the functional heterogeneity of AcbSh neurons, primarily within the motivational space of reward and aversion. Several studies suggest that this heterogeneity can be mapped along the dorsal-ventral and rostral-caudal axis of AcbSh (Al-Hasani et al., 2015; Richard et al., 2013). For example, photoactivation of ventrallypositioned dynorphin-containing AcbSh neurons can be aversive while photoactivation of these neurons in dorsomedial AcbSh can be reinforcing (Al-Hasani et al., 2015). An interesting question then is whether suppression of conditioned responding is in part due to induction of an aversive motivational state. Observations from the present study as well as from others are inconsistent with production of an aversive affective state for the BLA-toAcbSh pathway. First, in the alcohol reinforced test, the average response latency was closely-timed to the offset of photoactivation and did not diminish across trials. When photoactivation was delivered on only half of the CS trials, cued alcohol seeking recovered on subsequent trials where laser stimulation was not delivered. These observations are inconsistent with photoactivation exerting a punishing signal to suppress behavior. Second, recent studies similarly involving BLA-to-AcbSh photoactivation and using similar frequency parameters $(20 \mathrm{~Hz})$ have shown that this pathway promotes reward-driven rather than aversion-driven behaviors. For example, animals will learn to nosepoke for photoactivation of this pathway, albeit at relatively low rates (Britt et al., 2012; Stuber et al., 2011); and activation of this pathway reduces depression- and anxiety-related behaviors, and promotes social behavior in stress-induced animals (Bagot et al., 2015). In a clever demonstration of the impact this circuit on both appetitive and consummatory behavior, Prado and colleagues found that licks reinforced by optogenetic activation of excitatory terminals (that could be of prefrontal, BLA, and thalamic origin) in the AcbSh increased over 7 days the likelihood of licking in non-stimualtion periods, while simultaneously suppressing licking during the stimulation period itself (Prado et al., 2016). Thus, the behavioral effects of photoactivation of BLA terminals in the AcbSh are unlikely mediated by aversion.

Worth considering is the possibility that the effects of photoactivation may be mediated, at least in part, through facilitation of extinction learning, particularly given the role of the BLA in encoding reward-related cues and extinction of appetitive behavior (Tye and Janak, 2007; Tye et al., 2010). However, this account is inconsistent with the finding that photoactivation appeared to impact performance on the first extinction alcohol CS trial and that on reinforced CS trials the behavior-suppressing effects of photoactivation did not persist through the entire duration of the CS. Thus, the influence in these experiments is likely specific to performance rather than learning.

\section{Amygdala-striatal control over hypothalamic appetitive function}

The AcbSh contains both D1R- and D2R-expressing GABAergic medium spiny projection neurons (MSNs). Recent findings suggest that D1R-MSNs control feeding through their inhibitory actions on GABAergic neurons in the lateral hypothalamus, as demonstrated by a 
decrease in feeding upon photoexcitation of this pathway (O'Connor et al., 2015). We speculate that this innate mode of control over feeding via D1R-MSNs, thought to adaptively inhibit feeding in the presence of environmental threat (Kelley, 2004; O'Connor et al., 2015) may be coopted by photoactivation of BLA terminals in AcbSh to enable control over alcohol-motivated behavior. This is in agreement with the working hypothesis advanced by Baldo and Kelley (2007) of the AcbSh as a 'circuit breaker' wherein strong excitatory drive can interrupt feeding mediated by disinhibition of downstream feeding circuits under control of GABAergic medium spiny neuron efferents. The generalizability of a "feeding control" system to an "alcohol drinking control" system recapitulates the overlap in neural substrates mediating reinforcement from drugs of abuse and natural rewards (Volkow et al., 2008, 2012). Finally, although unknown whether BLA projections preferentially target AcbSh D1-MSNs, a projection bias for BLA neurons to D1-MSNs has been demonstrated for the dorsal striatum (Wall et al., 2013), raising the possibility that BLA inputs to AcbSh may directly access AcbSh neurons that preferentially project to lateral hypothalamus. Projections from the AcbSh to other regions, such as the ventral pallidum, may also be important for these effects. In addition, here we have focused on the AcbSh, but feeding can be impacted following electrical manipulations of the core subregion as well (Krause et al., 2010). Finally, the possibility that long-lasting inhibitions in MSN firing are permissive for/disinhibit other motor programs besides feeding is likely, and has been proposed (Nicola et al., 2004; Taha and Fields, 2005, 2006).

In summary, we confirm the hypothesis tested here, that activation of excitatory BLA-toAcbSh pathway decreases, not increases, the conditioned motivational properties of rewardpredictive cues as well as unconditioned consummatory responses necessary for alcohol drinking. These findings suggest that top-down control from the BLA to the AcbSh can override appetitive motivational signals and interrupt responses for orally-consumed rewards, including alcohol.

\section{Acknowledgments}

This work was supported by NIH grants AA014925 and DA035943 to PHJ.

\section{References}

Al-Hasani R, McCall JG, Shin G, Gomez AM, Schmitz GP, Bernardi JM, Pyo C-O, Park SI, Marcinkiewcz CM, Crowley NA, et al. Distinct Subpopulations of Nucleus Accumbens Dynorphin Neurons Drive Aversion and Reward. Neuron. 2015; 87:1063-1077. [PubMed: 26335648]

Ambroggi F, Ishikawa A, Fields HL, Nicola SM. Basolateral amygdala neurons facilitate rewardseeking behavior by exciting nucleus accumbens neurons. Neuron. 2008; 59:648-661. [PubMed: 18760700]

Bagot RC, Parise EM, Peña CJ, Zhang H-X, Maze I, Chaudhury D, Persaud B, Cachope R, BolañosGuzmán CA, Cheer J, et al. Ventral hippocampal afferents to the nucleus accumbens regulate susceptibility to depression. Nat. Commun. 2015; 6:7062. [PubMed: 25952660]

Bass CE, Grinevich VP, Gioia D, Day-Brown JD, Bonin KD, Stuber GD, Weiner JL, Budygin EA. Optogenetic stimulation of VTA dopamine neurons reveals that tonic but not phasic patterns of dopamine transmission reduce ethanol self-administration. Front. Behav. Neurosci. 2013; 7:173. [PubMed: 24324415] 
Beyeler A, Namburi P, Glober GF, Simonnet C, Calhoon GG, Conyers GF, Luck R, Wildes CP, Tye KM. Divergent Routing of Positive and Negative Information from the Amygdala during Memory Retrieval. Neuron. 2016; 90:348-361. [PubMed: 27041499]

Brandon TH, Vidrine JI, Litvin EB. Relapse and relapse prevention. Annu. Rev. Clin. Psychol. 2007; 3:257-284. [PubMed: 17716056]

Britt JP, Benaliouad F, McDevitt RA, Stuber GD, Wise RA, Bonci A. Synaptic and behavioral profile of multiple glutamatergic inputs to the nucleus accumbens. Neuron. 2012; 76:790-803. [PubMed: 23177963]

Brog JS, Salyapongse A, Deutch AY, Zahm DS. The patterns of afferent innervation of the core and shell in the "accumbens" part of the rat ventral striatum: immunohistochemical detection of retrogradely transported fluoro-gold. J. Comp. Neurol. 1993; 338:255-278. [PubMed: 8308171]

Chang SE, Smith KS. An omission procedure reorganizes the microstructure of sign-tracking while preserving incentive salience. Learn. Mem. 2016; 23:151-155. [PubMed: 26980782]

Chaudhri N, Sahuque LL, Cone JJ, Janak PH. Reinstated ethanol-seeking in rats is modulated by environmental context and requires the nucleus accumbens core. Eur. J. Neurosci. 2008a; 28:22882298. [PubMed: 19046372]

Chaudhri N, Sahuque LL, Janak PH. Context-induced relapse of conditioned behavioral responding to ethanol cues in rats. Biol. Psychiatry. 2008b; 64:203-210. [PubMed: 18423574]

Chaudhri N, Sahuque LL, Schairer WW, Janak PH. Separable Roles of the Nucleus Accumbens Core and Shell in Context- and Cue-Induced Alcohol-Seeking. Neuropsychopharmacology. 2010; 35:783-791. [PubMed: 19924113]

Chaudhri N, Woods CA, Sahuque LL, Gill TM, Janak PH. Unilateral inactivation of the basolateral amygdala attenuates context-induced renewal of Pavlovian-conditioned alcohol-seeking. Eur. J. Neurosci. 2013; 38:2751-2761. [PubMed: 23758059]

Corbit LH, Janak PH. Ethanol-Associated Cues Produce General Pavlovian-Instrumental Transfer. Alcohol. Clin. Exp. Res. 2007; 31:766-774. [PubMed: 17378919]

Corbit LH, Janak PH. Changes in the Influence of Alcohol-Paired Stimuli on Alcohol Seeking across Extended Training. Front. Psychiatry. 2016; 7:169. [PubMed: 27777560]

Courtney KE, Schacht JP, Hutchison K, Roche DJO, Ray LA. Neural substrates of cue reactivity: association with treatment outcomes and relapse. Addict. Biol. 2016; 21:3-22. [PubMed: 26435524]

Dayas CV, McGranahan TM, Martin-Fardon R, Weiss F. Stimuli Linked to Ethanol Availability Activate Hypothalamic CART and Orexin Neurons in a Reinstatement Model of Relapse. Addict. Stress Relapse Vulnerability. 2008; 63:152-157.

Do-Monte FH, Minier-Toribio A, Quiñones-Laracuente K, Medina-Colón EM, Quirk GJ. Thalamic Regulation of Sucrose Seeking during Unexpected Reward Omission. Neuron. 2017; 94:388400.e4. [PubMed: 28426970]

Everitt BJ, Cador M, Robbins TW. Interactions between the amygdala and ventral striatum in stimulusreward associations: studies using a second-order schedule of sexual reinforcement. Neuroscience. 1989; 30:63-75. [PubMed: 2664555]

Everitt BJ, Parkinson JA, Olmstead MC, Arroyo M, Robledo P, Robbins TW. Associative processes in addiction and reward. The role of amygdala-ventral striatal subsystems. Ann. N. Y. Acad. Sci. 1999; 877:412-438. [PubMed: 10415662]

Field M, Cox WM. Attentional bias in addictive behaviors: a review of its development, causes, and consequences. Drug Alcohol Depend. 2008; 97:1-20. [PubMed: 18479844]

Field M, Duka T. Cues paired with a low dose of alcohol acquire conditioned incentive properties in social drinkers. Psychopharmacology (Berl.). 2002; 159:325-334. [PubMed: 11862366]

Gremel CM, Cunningham CL. Roles of the nucleus accumbens and amygdala in the acquisition and expression of ethanol-conditioned behavior in mice. J. Neurosci. Off. J. Soc. Neurosci. 2008; 28:1076-1084.

Hauser SR, Deehan GA, Knight CP, Toalston JE, McBride WJ, Rodd ZA. Parameters of ContextInduced Ethanol (EtOH)-Seeking in Alcohol-Preferring (P) Rats: Temporal Analysis, Effects of Repeated Deprivation, and EtOH Priming Injections. Alcohol. Clin. Exp. Res. 2016; 40:22292239. [PubMed: 27696522] 
Heinz A, Beck A, Grüsser SM, Grace AA, Wrase J. Identifying the neural circuitry of alcohol craving and relapse vulnerability: Neural circuitry of alcohol craving and relapse vulnerability. Addict. Biol. 2009; 14:108-118. [PubMed: 18855799]

Holland PC, Asem JSA, Galvin CP, Keeney CH, Hsu M, Miller A, Zhou V. Blocking in autoshaped lever-pressing procedures with rats. Learn. Behav. 2014; 42:1-21. [PubMed: 24002941]

Janak PH, Chang JY, Woodward DJ. Neuronal spike activity in the nucleus accumbens of behaving rats during ethanol self-administration. Brain Res. 1999; 817:172-184. [PubMed: 9889360]

Jasinska AJ, Stein EA, Kaiser J, Naumer MJ, Yalachkov Y. Factors modulating neural reactivity to drug cues in addiction: a survey of human neuroimaging studies. Neurosci. Biobehav. Rev. 2014; 38:1-16. [PubMed: 24211373]

Jennings JH, Sparta DR, Stamatakis AM, Ung RL, Pleil KE, Kash TL, Stuber GD. Distinct extended amygdala circuits for divergent motivational states. Nature. 2013; 496:224-228. [PubMed: 23515155]

Jones A, Christiansen P, Nederkoorn C, Houben K, Field M. Fluctuating disinhibition: implications for the understanding and treatment of alcohol and other substance use disorders. Front. Psychiatry. 2013; 4:140. [PubMed: 24155728]

Kelley AE. Ventral striatal control of appetitive motivation: role in ingestive behavior and rewardrelated learning. Neurosci. Biobehav. Rev. 2004; 27:765-776. [PubMed: 15019426]

Kelley AE, Swanson CJ. Feeding induced by blockade of AMPA and kainate receptors within the ventral striatum: a microinfusion mapping study. Behav. Brain Res. 1997; 89:107-113. [PubMed: 9475619]

Kelley AE, Domesick VB, Nauta WJ. The amygdalostriatal projection in the rat--an anatomical study by anterograde and retrograde tracing methods. Neuroscience. 1982; 7:615-630. [PubMed: 7070669]

Knight CP, Hauser SR, Deehan GA, Toalston JE, McBride WJ, Rodd ZA. Oral Conditioned Cues Can Enhance or Inhibit Ethanol (EtOH)-Seeking and EtOH-Relapse Drinking by Alcohol-Preferring (P) Rats. Alcohol. Clin. Exp. Res. 2016; 40:906-915. [PubMed: 27038599]

Koshikawa, N., Fujita, S., Adachi, K. Behavioral pharmacology of orofacial movement disorders. In: Masayuki Kobayashi Koichi Iwata, NK., Waddington, John L., editors. International Review of Neurobiology. Academic Press; 2011. p. 1-38.

Krank MD. Pavlovian conditioning with ethanol: sign-tracking (autoshaping), conditioned incentive, and ethanol self-administration. Alcohol. Clin. Exp. Res. 2003; 27:1592-1598. [PubMed: 14574229]

Krank MD, O’Neill S, Squarey K, Jacob J. Goal- and signal-directed incentive: conditioned approach, seeking, and consumption established with unsweetened alcohol in rats. Psychopharmacology (Berl.). 2008; 196:397-405. [PubMed: 17965977]

Krause M, German PW, Taha SA, Fields HL. A Pause in Nucleus Accumbens Neuron Firing Is Required to Initiate and Maintain Feeding. J. Neurosci. 2010; 30:4746-4756. [PubMed: 20357125]

Kreusch F, Vilenne A, Quertemont E. Response inhibition toward alcohol-related cues using an alcohol go/no-go task in problem and non-problem drinkers. Addict. Behav. 2013; 38:2520-2528. [PubMed: 23773960]

Maldonado-Irizarry CS, Swanson CJ, Kelley AE. Glutamate receptors in the nucleus accumbens shell control feeding behavior via the lateral hypothalamus. J. Neurosci. Off. J. Soc. Neurosci. 1995; 15:6779-6788.

McDonald AJ. Topographical organization of amygdaloid projections to the caudatoputamen, nucleus accumbens, and related striatal-like areas of the rat brain. Neuroscience. 1991; 44:15-33. [PubMed: 1722890]

Mikhailova MA, Bass CE, Grinevich VP, Chapell AM, Deal AL, Bonin KD, Weiner JL, Gainetdinov RR, Budygin EA. Optogenetically-induced tonic dopamine release from VTA-nucleus accumbens projections inhibits reward consummatory behaviors. Neuroscience. 2016; 333:54-64. [PubMed: 27421228]

Millan EZ, Furlong TM, McNally GP. Accumbens Shell-Hypothalamus Interactions Mediate Extinction of Alcohol Seeking. J. Neurosci. 2010; 30:4626-4635. [PubMed: 20357113] 
Millan EZ, Reese RM, Grossman CD, Chaudhri N, Janak PH. Nucleus Accumbens and Posterior Amygdala Mediate Cue-Triggered Alcohol Seeking and Suppress Behavior During the Omission of Alcohol-Predictive Cues. Neuropsychopharmacology. 2015

Naeem M, White NM. Parallel learning in an autoshaping paradigm. Behav. Neurosci. 2016; 130:376392. [PubMed: 27454485]

Namburi P, Beyeler A, Yorozu S, Calhoon GG, Halbert SA, Wichmann R, Holden SS, Mertens KL, Anahtar M, Felix-Ortiz AC, et al. A circuit mechanism for differentiating positive and negative associations. Nature. 2015; 520:675-678. [PubMed: 25925480]

Nicola SM, Yun IA, Wakabayashi KT, Fields HL. Firing of nucleus accumbens neurons during the consummatory phase of a discriminative stimulus task depends on previous reward predictive cues. J. Neurophysiol. 2004; 91:1866-1882. [PubMed: 14645378]

Nie H, Janak PH. Comparison of reinstatement of ethanol- and sucrose-seeking by conditioned stimuli and priming injections of allopregnanolone after extinction in rats. Psychopharmacology (Berl.). 2003; 168:222-228. [PubMed: 12719962]

Nie H, Rewal M, Gill TM, Ron D, Janak PH. Extrasynaptic delta-containing GABAA receptors in the nucleus accumbens dorsomedial shell contribute to alcohol intake. Proc. Natl. Acad. Sci. U. S. A. 2011; 108:4459-4464. [PubMed: 21368141]

O'Connor EC, Kremer Y, Lefort S, Harada M, Pascoli V, Rohner C, Lüscher C. Accumbal D1R Neurons Projecting to Lateral Hypothalamus Authorize Feeding. Neuron. 2015; 88:553-564. [PubMed: 26593092]

Prado L, Luis-Islas J, Sandoval OI, Puron L, Gil MM, Luna A, Arias-García MA, Galarraga E, Simon SA, Gutierrez R. Activation of Glutamatergic Fibers in the Anterior NAc Shell Modulates Reward Activity in the aNAcSh, the Lateral Hypothalamus, and Medial Prefrontal Cortex and Transiently Stops Feeding. J. Neurosci. Off. J. Soc. Neurosci. 2016; 36:12511-12529.

Prinssen E, Balestra W, Bemelmans F, Cools A. Evidence for a role of the shell of the nucleus accumbens in oral behavior of freely moving rats. J. Neurosci. 1994; 14:1555-1562. [PubMed: 7907364]

Remedios J, Woods C, Tardif C, Janak PH, Chaudhri N. Pavlovian-conditioned alcohol-seeking behavior in rats is invigorated by the interaction between discrete and contextual alcohol cues: implications for relapse. Brain Behav. 2014; 4:278-289. [PubMed: 24683519]

Richard JM, Fields HL. Mu-opioid receptor activation in the medial shell of nucleus accumbens promotes alcohol consumption, self-administration and cue-induced reinstatement. Neuropharmacology. 2016; 108:14-23. [PubMed: 27089981]

Richard JM, Plawecki AM, Berridge KC. Nucleus accumbens GABAergic inhibition generates intense eating and fear that resists environmental retuning and needs no local dopamine. Eur. J. Neurosci. 2013; 37:1789-1802. [PubMed: 23551138]

Roitman MF, Wheeler RA, Carelli RM. Nucleus Accumbens Neurons Are Innately Tuned for Rewarding and Aversive Taste Stimuli, Encode Their Predictors, and Are Linked to Motor Output. Neuron. 2005; 45:587-597. [PubMed: 15721244]

Roitman MF, Wheeler RA, Tiesinga PHE, Roitman JD, Carelli RM. Hedonic and nucleus accumbens neural responses to a natural reward are regulated by aversive conditioning. Learn. Mem. 2010; 17:539-546. [PubMed: 20971936]

Schacht JP, Anton RF, Myrick H. Functional neuroimaging studies of alcohol cue reactivity: a quantitative meta-analysis and systematic review. Addict. Biol. 2013; 18:121-133. [PubMed: 22574861]

Selleck RA, Baldo BA. Feeding-modulatory effects of mu-opioids in the medial prefrontal cortex: a review of recent findings and comparison to opioid actions in the nucleus accumbens. Psychopharmacology (Berl.). 2017; 234:1439-1449. [PubMed: 28054099]

Shinonaga Y, Takada M, Mizuno N. Topographic organization of collateral projections from the basolateral amygdaloid nucleus to both the prefrontal cortex and nucleus accumbens in the rat. Neuroscience. 1994; 58(2):389-397. [PubMed: 8152545]

Simms JA, Steensland P, Medina B, Abernathy KE, Chandler LJ, Wise R, Bartlett SE. Intermittent Access to 20\% Ethanol Induces High Ethanol Consumption in Long-Evans and Wistar Rats. Alcohol. Clin. Exp. Res. 2008; 32:1816-1823. [PubMed: 18671810] 
Sparks LM, Sciascia JM, Ayorech Z, Chaudhri N. Vendor differences in alcohol consumption and the contribution of dopamine receptors to Pavlovian-conditioned alcohol-seeking in Long-Evans rats. Psychopharmacology (Berl.). 2014; 231:753-764. [PubMed: 24096535]

Srey CS, Maddux J-MN, Chaudhri N. The attribution of incentive salience to Pavlovian alcohol cues: a shift from goal-tracking to sign-tracking. Front. Behav. Neurosci. 2015; 9:54. [PubMed: 25784867]

Stratford TR, Kelley AE. GABA in the Nucleus Accumbens Shell Participates in the Central Regulation of Feeding Behavior. J. Neurosci. 1997; 17:4434-4440. [PubMed: 9151760]

Stratford TR, Wirtshafter D. Opposite effects on the ingestion of ethanol and sucrose solutions after injections of muscimol into the nucleus accumbens shell. Behav. Brain Res. 2011; 216:514-518. [PubMed: 20804790]

Stratford TR, Swanson CJ, Kelley A. Specific changes in food intake elicited by blockade or activation of glutamate receptors in the nucleus accumbens shell. Behav. Brain Res. 1998; 93:43-50. [PubMed: 9659985]

Stuber GD, Sparta DR, Stamatakis AM, van Leeuwen WA, Hardjoprajitno JE, Cho S, Tye KM, Kempadoo KA, Zhang F, Deisseroth K, et al. Excitatory transmission from the amygdala to nucleus accumbens facilitates reward seeking. Nature. 2011; 475:377-380. [PubMed: 21716290]

Sutton MA, Schmidt EF, Choi K-H, Schad CA, Whisler K, Simmons D, Karanian DA, Monteggia LM, Neve RL, Self DW. Extinction-induced upregulation in AMPA receptors reduces cocaine-seeking behaviour. Nature. 2003; 421:70-75. [PubMed: 12511956]

Taha SA, Fields HL. Encoding of palatability and appetitive behaviors by distinct neuronal populations in the nucleus accumbens. J. Neurosci. Off. J. Soc. Neurosci. 2005; 25:1193-1202.

Taha SA, Fields HL. Inhibitions of nucleus accumbens neurons encode a gating signal for rewarddirected behavior. J. Neurosci. Off. J. Soc. Neurosci. 2006; 26:217-222.

Thompson RH, Swanson LW. Hypothesis-driven structural connectivity analysis supports network over hierarchical model of brain architecture. Proc. Natl. Acad. Sci. 2010; 107:15235-15239. [PubMed: 20696892]

Tye KM, Janak PH. Amygdala neurons differentially encode motivation and reinforcement. J. Neurosci. Off. J. Soc. Neurosci. 2007; 27:3937-3945.

Tye KM, Cone JJ, Schairer WW, Janak PH. Amygdala neural encoding of the absence of reward during extinction. J. Neurosci. Off. J. Soc. Neurosci. 2010; 30:116-125.

Volkow ND, Wang G-J, Fowler JS, Telang F. Overlapping neuronal circuits in addiction and obesity: evidence of systems pathology. Philos. Trans. R. Soc. B Biol. Sci. 2008; 363:3191-3200.

Volkow, ND., Wang, GJ., Fowler, JS., Tomasi, D., Baler, R. Food and Drug Reward: Overlapping Circuits in Human Obesity and Addiction. In: Carter, SC., Dalley, WJ., editors. Brain Imaging in Behavioral Neuroscience. Berlin, Heidelberg: Springer Berlin Heidelberg; 2012. p. 1-24.

Wall NR, De La Parra M, Callaway EM, Kreitzer AC. Differential Innervation of Direct-and IndirectPathway Striatal Projection Neurons. Neuron. 2013; 79:347-360. [PubMed: 23810541]

Wiers CE, Stelzel C, Park SQ, Gawron CK, Ludwig VU, Gutwinski S, Heinz A, Lindenmeyer J, Wiers $\mathrm{RW}$, Walter H, et al. Neural correlates of alcohol-approach bias in alcohol addiction: the spirit is willing but the flesh is weak for spirits. Neuropsychopharmacol. Off. Publ. Am. Coll. Neuropsychopharmacol. 2014; 39:688-697.

Zhang M, Kelley AE. Intake of saccharin, salt, and ethanol solutions is increased by infusion of a mu opioid agonist into the nucleus accumbens. Psychopharmacology (Berl.). 2002; 159:415-423. [PubMed: 11823894] 


\section{Highlights}

- Optogenetic activation of basolateral amygdala (BLA) inputs to accumbens shell (AcbSh) reduced cue-induced alcohol seeking

- Optogenetic activation of BLA inputs to AcbSh also reduced cue-induced sucrose seeking behavior

- Finally, optogenetic activation of BLA inputs to AcbSh decreased free consumption of alcohol from a drinking spout

- The findings indicate excitatory input to AcbSh can gate conditioned and unconditioned consummatory responses for alcohol 


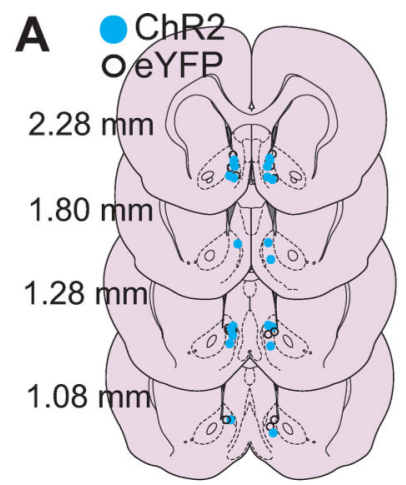

B

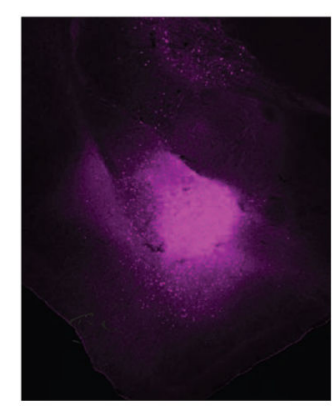

Non-Reinforced

EtOH Cue

D

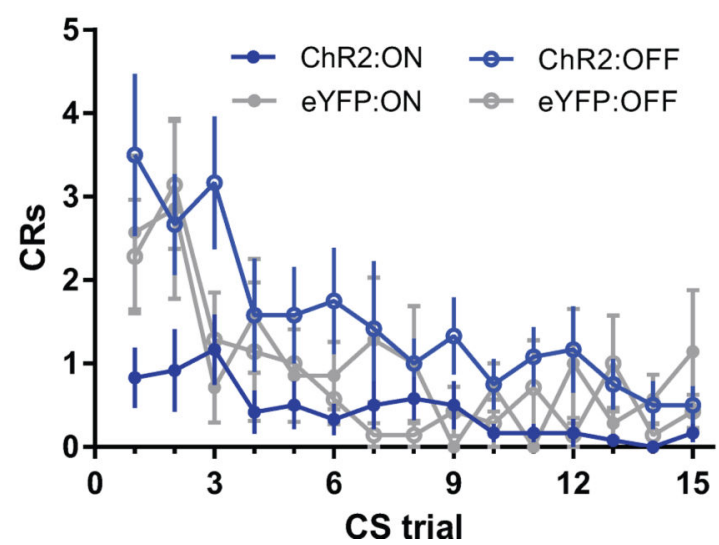

C

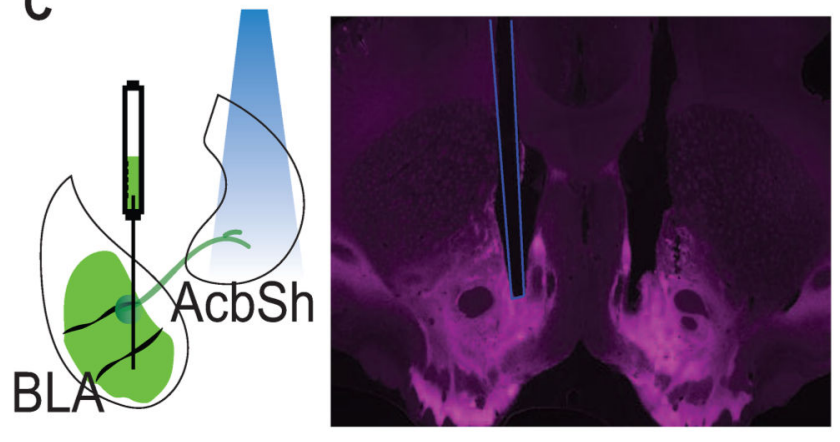

E

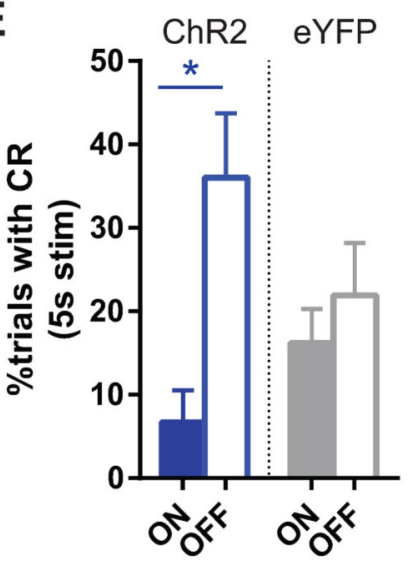

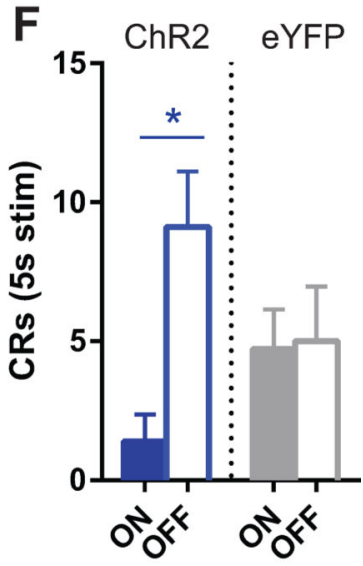

Figure 1. Photoactivation of BLA terminals in AcbSh decreases cued alcohol seeking in extinction $(\mathrm{ChR} 2, N=10 ;$ eYFP, $N=7)$

(A) Ventral tip of optic fiber cannulae are mapped on schematic coronal sections labeled with rostrocaudal distance $(\mathrm{mm})$ from bregma. Blue circles $=\mathrm{ChR} 2$ subjects; White circles $=$ eYFP controls. (B) $5 \times$ magnification photomicrograph depicting example ChR2-eYFP expression (magenta), localized within the BLA. (C) Schematic and 5x magnification photomicrograph of ChR2-eYFP expressing anterograde projections from BLA in nucleus accumbens. White arrowhead indicates ventral tip of the optic cannula in AcbSh. (D-F), Alcohol extinction cue test. Schematic in (D) shows photoactivation epoch relative to CS. During the "On" condition photoactivation was restricted to first $5 \mathrm{~s}$ of each 10s CS trial. On a different day, during the "Off" condition, photostimualtion was withheld. (D) Mean $( \pm$ SEM) frequency of port entries during each CS trial. Port entry conditioned responses (CRs) were significantly reduced during the "on" test day compared to the "off" test day for ChR2 $\left(\mathrm{F}_{(1,9)}=12.05, p<.05\right)$ but not eYFP (p>.05) rats. (E) Mean ( \pm SEM) percentage of trials in which the CS elicited a CR during the photoactivation window (first $5 \mathrm{~s}$ of CS). Simple effects "on" versus "off" for ChR2: $\mathrm{F}_{(1,9)}=22.46, p<.05$; eYFP: $\mathrm{p}>.05$. (F) Mean $( \pm$ SEM) frequency of total CRs occurring within the photoactivation window (first $5 \mathrm{~s}$ of CS). Simple effects "on" versus "off" for ChR2: $\mathrm{F}_{(1,9)}=18.65, p<.05$; eYFP: $\mathrm{p}>.05$. Abbreviations: AP, anterior-posterior; AcbC, nucleus accumbens core; AcbSh, nucleus accumbens shell; BLA, basolateral amygdala; BLP, basolateral amygdala, posterior part; 
BMP, basomedial amygdala, posterior part; $\mathrm{CeA}$, central amygdala; cc, corpus callosum; $\mathrm{CPu}$; LS, lateral septum; LV, lateral ventricle; OT, optic tract. *indicates $\mathrm{p}<.05$ for simple effect comparison during "on" versus "off" condition. 


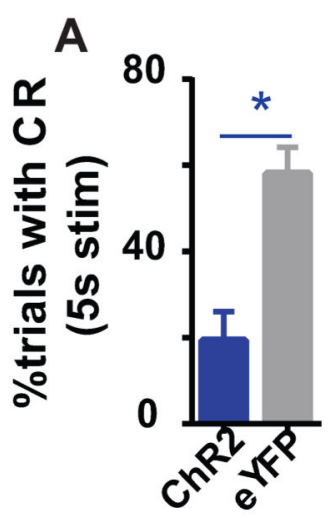

B

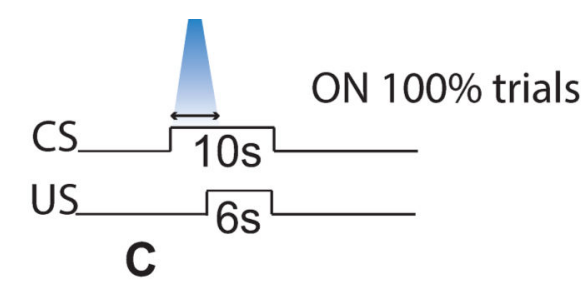

CS trial

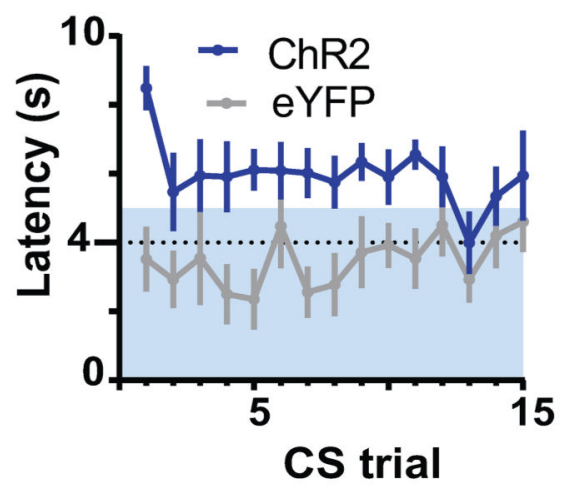

Reinforced Test II $\mathrm{EtOH}$ delivered with laser onset

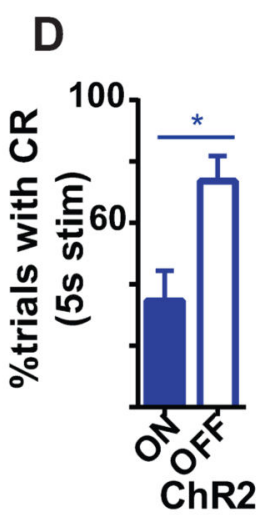

E

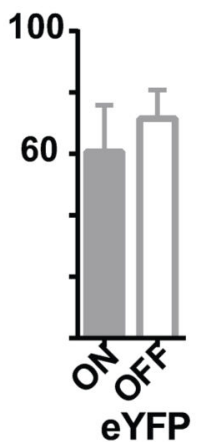

F

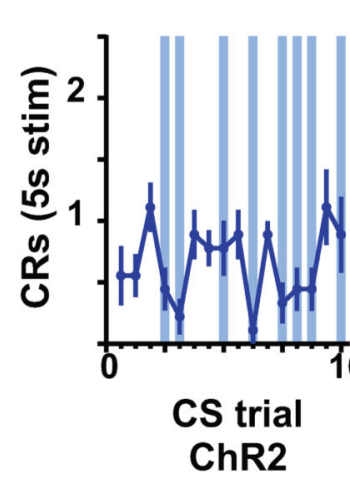

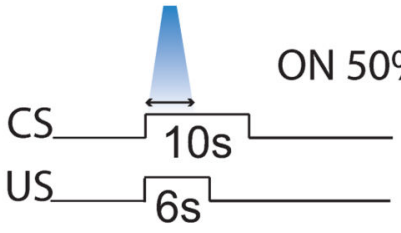

G

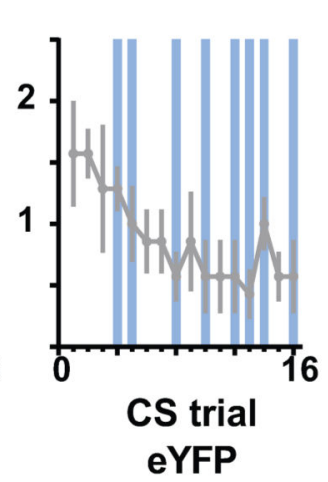

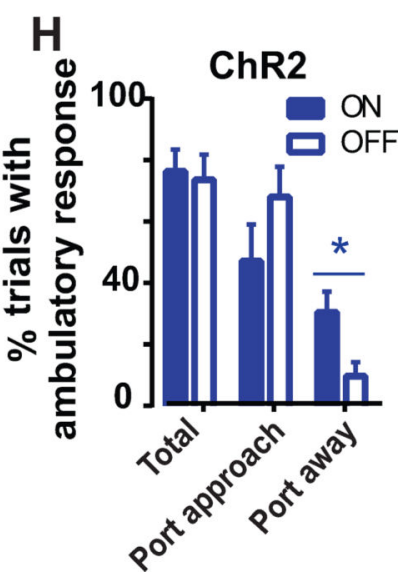

Figure 2. Photoactivation of BLA terminals in AcbSh decreases reinforced cued alcohol seeking During Reinforced Test I (A-C; ChR2, $N=10$; eYFP, $N=7$ ), photoactivation co-occurred with CS onset and overlapped the $1^{\text {st }}$ sec of alcohol delivery. (A) mean $( \pm$ SEM) percentage of trials with a port entry CR during the first 5 s of CS (photoactivation period); (B) mean ( \pm SEM) frequency of port entry CRs during the first 5s of CS across CS trials; and (C), mean $( \pm$ SEM) latency to initiate a CR across CS trials. The latency data excludes trials in which rats omitted a conditioned response. Blue shaded area indicates photoactivation period of the CS. Dotted line indicates onset of alcohol delivery. During Reinforced Test II (D-H; ChR2, $N=9$; eYFP, $N=7$ ), photoactivation and alcohol delivery co-occurred with CS onset. (D,E) mean $( \pm$ SEM) percentage of trials with a CR during the first 5 s of CS; and (F,G) mean $( \pm$ SEM) frequency of CRs during the first 5 s of CS across CS trials. Filled columns = laser 
ON; unfilled = laser OFF. Vertical blue lines indicate CS trials paired with photoactivation. (H) Mean $( \pm$ SEM) percentage of trials with an ambulatory response sorted for laser ON (Blue filled colums) and laser OFF (unfilled columns) trials. Total $=$ all trials with an ambulatory response; Port approach $=$ trials in which rat was locomoting towards reward port; Post away $=$ trials in which rat was locomoting away from reward port. *indicates $\mathrm{p}<$. 05 for simple effect comparison during "on" versus "off" condition. 


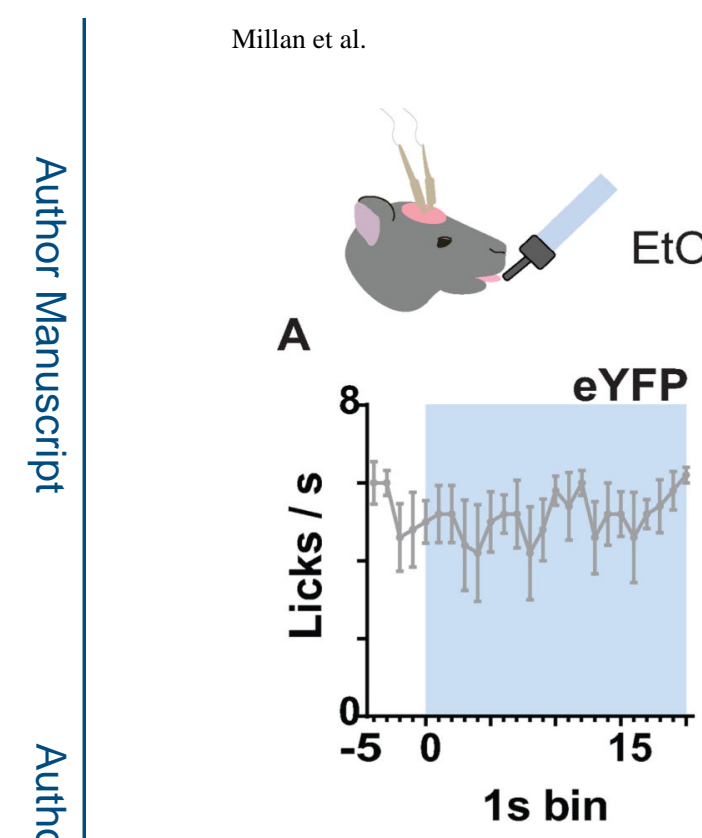

\section{tOH drinking}

B
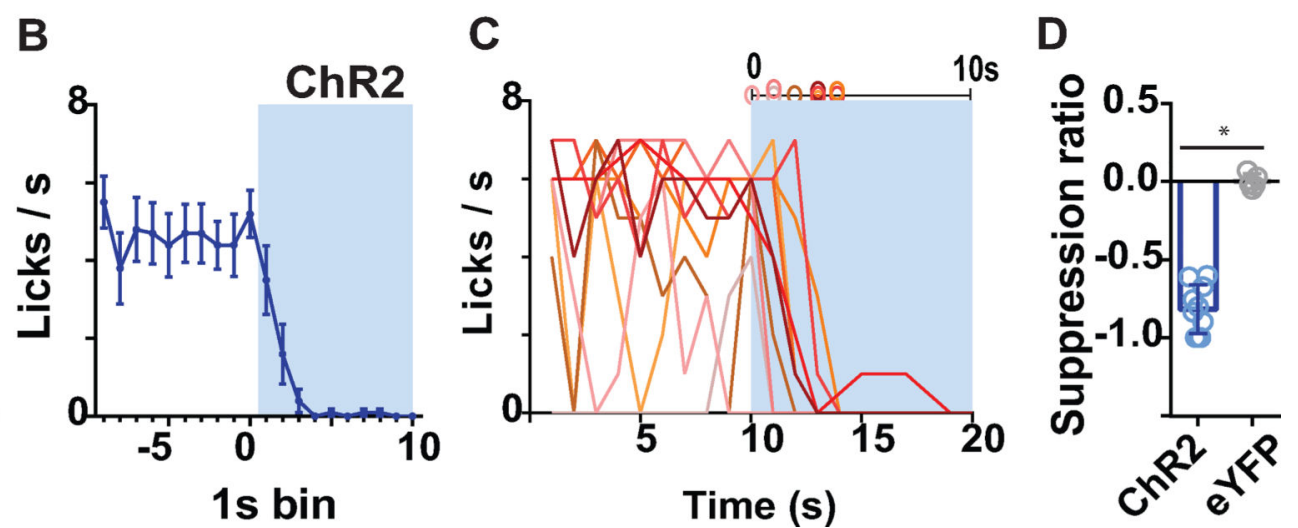

Figure 3. Photoactivation of BLA terminals in AcbSh arrests alcohol intake (ChR2, N=9; eYFP, $N=8$ )

(A) Mean $( \pm$ SEM) number of licks across 1 s time bins during pre-stimulation baseline and on the first 20s of photoactivation for control group eYFP, which received 120 s photoactivation $(N=6)$. (B) Mean $( \pm$ SEM) number of licks across 1 s time bins during prestimulation baseline and on the first 10s of photoactivation for ChR2. (C) Licks/sec for individual animals in group ChR2. (D) Mean $( \pm$ SEM) lick suppression ratio. 

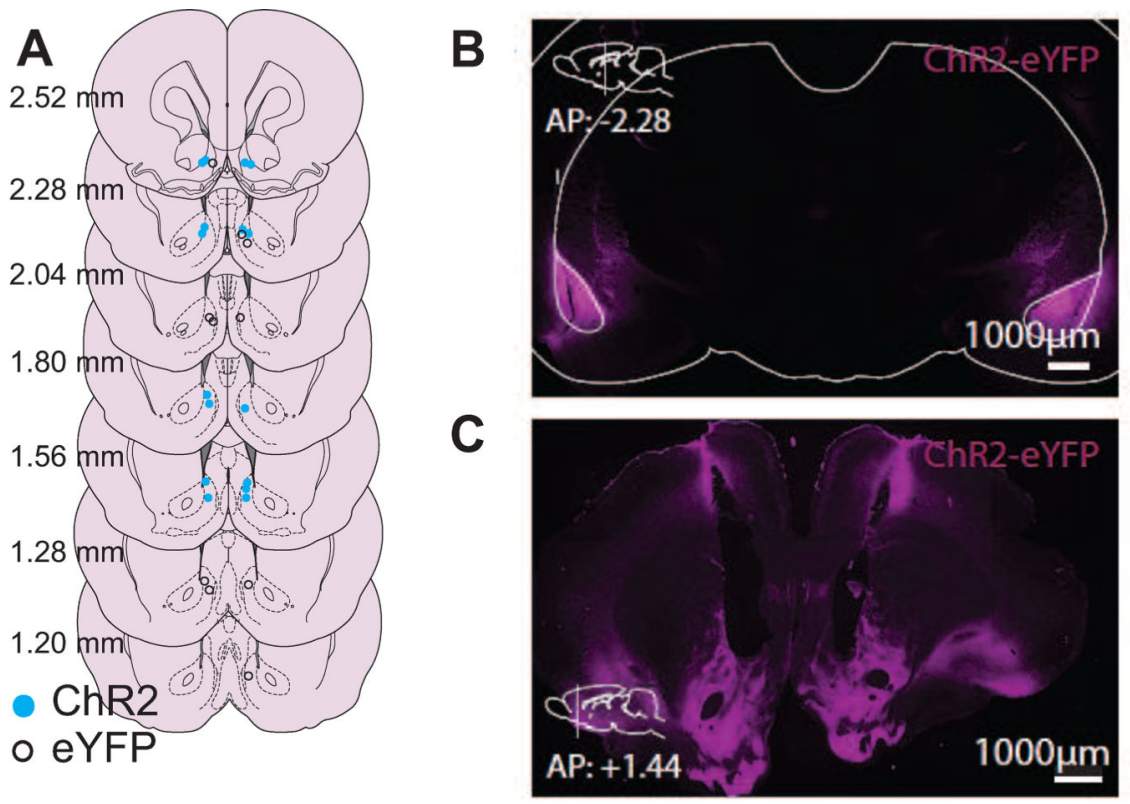

\section{Non-Reinforced Sucrose Cue}
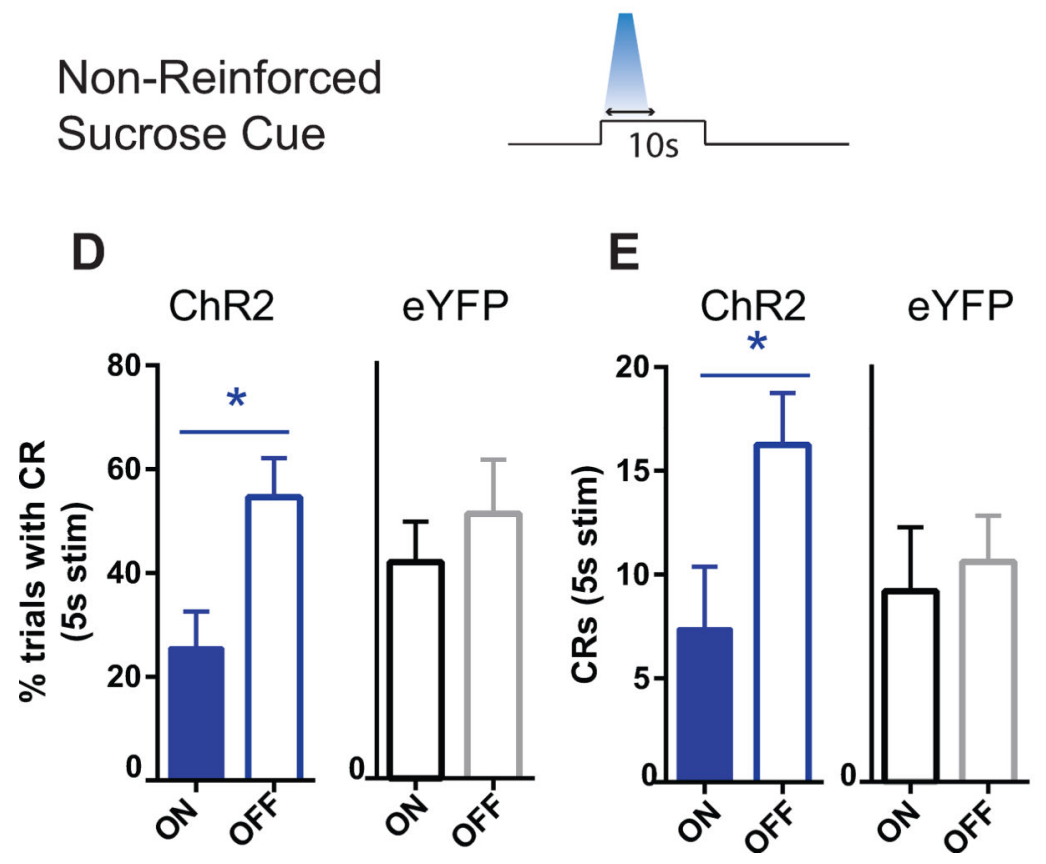

Figure 4. Photoactivation of BLA terminals in AcbSh reduces cued sucrose seeking in extinction (ChR2, $N=8$; eYFP, $N=5$ )

(A) Ventral tip of optic fiber cannulae are mapped on schematic coronal sections labeled with rostrocaudal distance $(\mathrm{mm})$ from bregma. Blue circles $=$ ChR2; white circles $=$ eYFP control. (B) 5× magnification photomicrograph depicting example ChR2-eYFP expression (magenta), localized within the BLA. (C) Schematic and 5× magnification photomicrograph of ChR2-eYFP expressing anterograde projections from BLA in nucleus accumbens. (D) Mean $( \pm$ SEM) percentage of trials in which the CS elicited a port entry CR during the 
photoactivation window (first 5 s of CS). (E) Mean ( \pm SEM) frequency of port entries during each CS trial. 


\section{Table 1}

Homecage alcohol access during the pre-exposure period.

\begin{tabular}{lll}
\hline & $\begin{array}{l}\text { Final access day } \\
\text { (pre-surgery) }\end{array}$ & $\begin{array}{l}\text { Final access day } \\
\text { (post-surgery) }\end{array}$ \\
\hline Photoactivation & & \\
$\mathrm{ChR} 2$ & $4.45 \pm 0.74 \mathrm{~g} / \mathrm{kg}$ & $5.96 \pm 0.58 \mathrm{~g} / \mathrm{kg}$ \\
$\mathrm{eYFP}$ & $4.67 \pm 0.57 \mathrm{~g} / \mathrm{kg}$ & $5.07 \pm 0.55 \mathrm{~g} / \mathrm{kg}$ \\
\hline
\end{tabular}

Mean \pm SEM intake. There were no significant differences between groups. 